\title{
Visiones compartidas de la Independencia y de la Revolución Mexi- cana. (2010) Palacio Prieto, José Luis (coord.) Fernández Flores, Ligia, Gómez-Aguado, Guadalupe, Muñoz Figueroa, Jorge (comp.). México: unAm-Centro de Enseñanza para Extranjeros.
}

José Rubén Romero Galván

IIH-UNAM

El ser humano es uno y diverso, incluso paradójico. Su realidad está construida de contrastes. Con ese juego de claroscuros y se enfrenta el historiador cuando se acerca al hombre como fue en el pasado para conocerlo, comprenderlo y explicarlo. Los resultados de tal empresa se proyectan hasta el presente, desde donde el historiador, - ser privilegiado- observa y realiza sus tareas que, al final, redundan en la mejor comprensión de un presente que, para nuestra desgracia, fluye de manera vertiginosa. A fin de cuentas, gracias a ese empeño de conocer, comprender y explicar el pasado, nos conocemos en el presente, porque lo que somos hoy, lo somos por lo que hemos sido en otro tiempo.

La empresa cuyo fin es explicar al hombre en su pasado sólo se resuelve de mejor manera cuando miradas diversas convergen en los acontecimientos objeto de tales empeños. De esta suerte, podemos afirmar que los hechos del pasado así mirados y analizados se ofrecen a nuestros ojos mostrándonos la diversidad de matices con los que en su momento ocurrieron. Es así que obtenemos, como enseñanza de gran valor, una clara conciencia de esos claroscuros y matices que caracterizan a la realidad humana.

El libro Visiones compartidas de la Independencia y de la Revolución Mexicana, surgió de una serie de conferencias con las que el Centro de Enseñanza para Extranjeros (CEPE) de la Universidad Nacional Autónoma de México (UNAM) conmemoró el año pasado sendos acontecimientos fundamentales de nuestra realidad actual. Esta edición preserva en el papel lo que se dijo en cada uno de esos actos académicos. Verva volant, scripta menent, las palabras vuelan, los escritos permanecen, es la expresión con la que los antiguos quisieron significar el peso de la palabra que se estampa sobre el papel y cuyas posibilidades de permanecer son mayores que aquellas que se pronuncian y que quedan, si acaso, en la memoria de los escuchas. La palabra escrita puede ser leída cuantas veces se quiera, es posible pensarla, repensarla, analizarla en varias ocasiones y desde diversas perspectivas y por ello es vehículo de conocimiento y conciencia de la realidad. La palabra dicha, aún cuando se haya apoyado en modulaciones de voz, en gestos enfáticos y pausas dramáticas, está condenada a permanecer, por supuesto con variantes, en la frágil memoria de quienes la es- 
cucharon, para, en muchas ocasiones, desaparecer con ellos. Por todo esto es sin duda un acierto encomiable la publicación de las conferencias que tuvieron lugar en el CEPE durante el año de nuestras conmemoraciones.

En el libro se reúnen trabajos que corresponden a diversas líneas de investigación. Ello constituye una gran riqueza, pues no sólo es muestra de la diversidad de enfoques con los que los historiadores nos enfrentamos al pasado, sino que ofrece también la posibilidad de que el lector entre en contacto con la compleja y abigarrada realidad de aquellos tiempos.

Está presente la historia política que explica el devenir de los hombres en el poder y que fue desde tiempos inmemoriales la historia por excelencia, la historia paradigmática, aquella que ha sido elemento sustancial de las justificaciones del ejercicio del poder que siempre ha estado reservado sólo a algunos cuantos, quienes, en muchas ocasiones, lo ejercen sin la autoridad moral que es el verdadero sustento de todo poder humano. Las sucesiones de gobernantes, las guerras y las revoluciones se cuentan entre los hechos cuyo tratamiento ha privilegiado la historia política.

Los trabajos aquí publicados que se inscriben en este rubro nos ponen en contacto con el carácter eminentemente trascendente de los acontecimientos conmemorados. Sus autores ponen en evidencia ante el lector que tanto la Independencia como la Revolución son hechos históricos que no se agotan en si mismos, que no quedan confinados en el pasado, sino que de algún modo impactaron los tiempos que les siguieron.

La historia cultural, cuya acta de nacimiento le fue expedida apenas en el siglo xx, abona también la riqueza del libro que presentamos. Las ideas, los impresos, las letras, la cultura en fin, no fueron, según se nos muestra, en nada ajenas a los complejos procesos que se generaron en torno a los acontecimientos de la Independencia y la Revolución. Si los hombres actuaron entonces, lo hicieron siempre con el espíritu henchido de ideas que se plasmaban en el papel o que venían de lo plasmando en el papel. El hombre será siempre hombre de pensamiento y hombre de acción. Aunque a veces el primero sea pobre y la segunda tímida.

Historia de la vida cotidiana, hija de la Escuela de los Annales, y repensada por la inglesa marxista Agnes Heller, y cuya génesis es posible encontrarla ya en el siglo antepasado en un historiador de la talla de Jules Michelet, encontró también un espacio en el mosaico que nos ofrece este libro. Cuánto nos beneficia cuestionarnos sobre qué ocurrió, por ejemplo, en torno a la Independencia en los hogares de la gente común y corriente como nosotros. Después de todo no todo mundo era Hidalgo o Calleja.

En el siglo xx, acaso prohijados por los proyectos no siempre claros ni bien justificados de globalización, que han buscado tornar uniforme al mundo, borrando fronteras y disimulando el carácter de cada país, en el siglo xx, surgió la inquietud por pensar a las identidades. Los historiadores comenzaron a darse a la tarea de 
acercarse a los procesos identitarios en el pasado y reflexionar sobre ellos para dar mayores luces a lo que sociólogos y antropólogos, desde las perspectivas de sus propias disciplinas, venían observando respecto de tales procesos. Sin duda, los trabajos contenidos en esta obra que abordan cuestiones vinculadas con la identidad aportan materia de reflexión sobre aquello que en la actualidad nos define como mexicanos.

Los autores que suscriben los trabajos publicados en este libro representan de manera perfecta las formas de hacer historia que acabo de mencionar. Pertenecen, además, a diferentes instituciones tanto de la unAm como de fuera de ella. En efecto, del Colegio de México colaboraron, Pilar Gonzalbo, Luis Fernando Lara y Rafael Olea; del Centro de Investigación y Docencia Económicas, Luis Felipe Barrón y del Instituto de Investigaciones Dr. José María Luis Mora se contó con la participación de Laura Suárez de la Torre y Guadalupe Villa. Nuestra Universidad está representada por la colaboración de Oscar Flores y Maricela González, del Instituto de Investigaciones Estéticas; de Fernando Curiel y Esther Martínez Luna, del Instituto de Investigaciones Filológicas; de Omar Moncada, del Instituto de Geografía; de Carmen Galindo, Mariana Ozuna y Miguel Soto, de la Facultad de Filosofía y Letras y del Centro de Enseñanza para Extranjeros, Guadalupe Gómez-Aguado.

Las colaboraciones de todos ellos han obrado en beneficio de la riqueza que caracteriza a los contenidos de esta publicación, pues cada uno de estos centros de investigación y docencia ha privilegiado líneas específicas de investigación, que reunidas en este volumen han permitido en su conjunto alcanzar una visión diversa de nuestra historia.

He dicho antes que la palabra escrita permanece. Es cierto. Pero debo confesar que hay de maneras a maneras de permanecer. La letra escrita puede perdurar en un documento escrito sin caligrafía, en el que los caracteres han sido puestos sin gusto alguno. Puede, en cambio, tratarse de un manuscrito en el que el amanuense se dio a la tarea de escribir con arte en verdad exquisito $y$, a tal grado, que produjo, a fin de cuentas, un bello ejemplar. Baste recordar los libros de horas de algunos nobles europeos que resguardan bibliotecas de aquel continente. Si de libros impresos se trata, los hay editados con el sólo fin de hacer llegar su contenido a los lectores. Los hay también de otra manera. Aquella en la que el editor se dio a la tarea de buscar los tipos de letra más apropiados, trabajó afanosamente por que la composición de cada página fuera equilibrada y en la que las ilustraciones aparecieran en un diálogo estético con el texto. Estaremos entonces ante un libro que ha dejado de ser sólo eso, un libro, para convertirse en un objeto cuyas características pueden permitir calificarlo como objeto artístico.

Visiones compartidas de la Independencia y de la Revolución Mexicana corresponden a las obras que describí al final. En efecto, el lector está ante un libro editado impecablemente. El diseño es en todos sentidos agradable a la vista, desde la selección de los tipos hasta el cuidado que se tuvo en escoger ilustraciones y fotografías. 
La obra, tiene sin duda atributos que lo colocan entre las mejores de aquellas que se produjeron a raíz de la conmemoración del centenario de la Revolución y el bicentenario de nuestra Independencia. Así lo que el ojo admira se corresponde con lo que el entendimiento aprecia por sus calidades. Contenido y forma se avienen en este libro sobresaliente en todo por sus calidades.

La labor que en este renglón llevaron a cabo el coordinador de la obra, José Luis Palacio, director del CEPE, y quienes tuvieron el encargo de compilar los materiales, de preparar su edición y darlos finalmente a la imprenta, me refiero a Ligia Fernández Flores, a Guadalupe Gómez Aguado y a Jorge Muñoz Figueroa, es en verdad encomiable, pues nos han entregado un libro, bello objeto, que vale tanto por lo que contiene como por lo que ofrece a los ojos. 